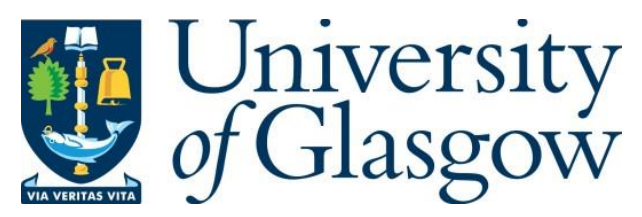

Ghannam, R. (2020) Do you call that a lab notebook? IEEE Potentials, 39(5), pp. 21-24.

There may be differences between this version and the published version. You are advised to consult the publisher's version if you wish to cite from it.

http://eprints.gla.ac.uk/209196/

Deposited on: 14 February 2020

Enlighten - Research publications by members of the University of Glasgow http://eprints.gla.ac.uk 


\title{
Do you call that a lab notebook?
}

\author{
Rami Ghannam \\ Engineering Education Research Group, \\ James Watt School of Engineering, University of Glasgow, UK.
}

\begin{abstract}
"Electronic laboratory notebooks? What are those?" At the start of every academic year, I prepare myself for a tug with my 3rd year engineering students about laboratory notebooks. More often than not, they either hand me a neatly written diary, or loose bits of paper that are half folded and randomly glued to the back cover of a jotter. At first, my students dismiss the idea of keeping a properly documented lab notebook. But I notice a change in attitude when they are introduced to electronic notebooks. In this article, I discuss the key benefits of maintaining an electronic notebook from the perspective of both staff and students. In fact, I believe that STEM students who adopt this basic research practice are more likely to gain some of the skills that are desperately needed by the constantly shifting job market.
\end{abstract}

The industrialist economy of the early $20^{\text {th }}$ century relied on traditional methods of teaching and learning, where students were taught facts and procedures. Unsurprisingly, the success of this teaching approach was measured by examining how well students can recall these facts and procedures. Social scientists and economists now argue that we are moving towards Knowledge Based Economies, which require a new breed of creative graduates who can solve real-world interdisciplinary problems, rather than graduates who can regurgitate isolated facts and detailed procedures. This means students must take responsibility for their own learning, reflect on their learning and develop their own sets of facts and procedures. And what better tool helps students with this benevolent endeavour than a properly maintained lab notebook? In fact, as a faculty member who is deeply involved in a transnational education (TNE) programme with the University of Glasgow, I regularly supervise a diverse group of engineering students based in Chengdu, London and Glasgow. When it comes to assessing and providing feedback to these students' practical work, I quickly realise that they have little experience in maintaining a lab notebook. But it's not entirely their fault. At least that's how I’m convinced.

Perhaps curricula in most schools and universities have failed this young breed in understanding how to deal with lab notebooks. Speaking for myself, I only appreciated how important these were when I moved to IBM Research in Zurich. I recognised that keeping a properly documented lab book was essential, especially when there were large sums of money involved, or if there were disputes regarding claims of ownership and discovery. Indeed, this is why some industries adopt very strict lab book policies. These big research companies need their employees to keep a detailed and well-maintained account of all their experimental work. Quite often, the notebook belongs to the company and must never be removed from its premises. 
So, what is a lab notebook? According to Howard Kanare, a laboratory notebook is among a scientist's most important tools. Some of the greatest minds in history kept detailed accounts of their experimental work. Classic examples include Leonardo di Vinci's notebook, which contained elaborate diagrams, drawings and text that neatly conveyed his experimental and thought process, as shown in figure 1. Therefore, when I am asked: "what goes inside it?", I literally say "everything!". Every experimental detail and idea needs to be written immediately as the work is performed. Moreover, each page must be dated and signed by the author. Each section must have a clear and descriptive heading. Writing needs to be legible and grammatically correct. Realities and deviations from the original plan need to be noted. Sketches, photographs and summaries must all be included.

Consequently, I sympathise with my students when we agonise about the difficulty in maintaining a paper-based notebook that meets the above requirements. I understand that paper notebooks can be hard to read, difficult to share, deteriorate over time and might even disappear! That is why software companies have now developed a range of products that uphold the great things about paper notebooks, but avoid some of their annoying limitations. Thanks to the early efforts of the pharmaceutical industry, ELN products were specifically designed to facilitate collaboration, to be easily searched and to be accessible from anywhere in the world. Instead of working in isolation, these collaborative software tools helped bring scientists together. In fact, by sharing and making visible the knowledge that has been learnt, research has shown that collaboration leads to better learning. As a result, there are now numerous examples of different ELN products being used in taught degree programmes, especially in the area of biochemistry and molecular biology.

\begin{abstract}
"But sir, which product should I choose?" Well, there are more than 50 commercial and open source products, the majority of which have been compiled by Harvard University. In my opinion, it doesn't matter which ELN product you use, as long as you stick to it. However, according to feedback that I received from surveys that were completed by 52 students, there was a clear preference for notetaking applications, such as Microsoft's OneNote. For the purpose of my investigations, I carried out a survey that tested six different ELN products in Glasgow University's TNE programme with the University of Electronic Science and Technology of China (UESTC). Here, my objective was to enhance student digital literacy, and to evaluate the effectiveness of ELNs in facilitating teamwork, collaboration and creativity. I also examined whether ELNs can be used to assess each group member's contributions fairly and accurately.
\end{abstract}

The six products I trialled were SciNote, LabArchives, RSpace, Benchling, OneNote and elabFTW. According to these surveys, almost $94 \%$ of my students were convinced that ELNs helped instructors assess each individual's contributions to a group project fairly and accurately. Judging from the two entries shown in figures 2 and 3, it is clear that the digital version is far easier for instructors like me to assess. Furthermore, since each student needs 
to create their own account, each log in can be recorded and archived. This feature allows instructors to carefully track each student's efforts and contributions, thereby alerting staff of any undesirable post-lab edits to assessed work. Moreover, nearly $90 \%$ of my students felt that ELN products helped them maintain a well-documented notebook, which contained all the embedded text, graphs and figures. During my interviews, students clearly liked ELNs due to their "ability to share information with other lab members", and their "accessibility from any computer or mobile device".

Still, ELNs are not perfect and their main disadvantages are their cost and their inability to draw freehand. Nevertheless, there are many commercial software packages, such as LabArchives, which can now overcome this freehand drawing limitation. Users can also create their images using third party freehand software tools such as SketchUp and import them back into their ELN. Furthermore, despite Glasgow University's efforts in providing licenses to specialist commercial products, approximately $40 \%$ of my surveyed students preferred free and open source software tools. Perhaps these packages gave them greater flexibility and enabled them to adapt the software to their needs.

I therefore strongly recommend that STEM students maintain good research practice by documenting all their experimental work in a lab notebook. There is a rich range of open source and commercial ELN products for digital natives. Despite their wide adoption in industry, less than $5 \%$ of academic labs currently use ELNs. Unfortunately, the main barriers to their adoption are licensing costs. However, approximately $40 \%$ of my surveyed students preferred open source software tools in comparison to specialist and commercial ELN products. Students have also reported a strong preference for notetaking tools such as Microsoft OneNote. Students therefore need to be aware of these software tools, since I have witnessed how such technologies have facilitated teamwork and collaboration between individuals. When used properly, I believe they can improve student learning and enable graduates to develop some of the necessary skills that are required by the $21^{\text {st }}$ century global job market. 


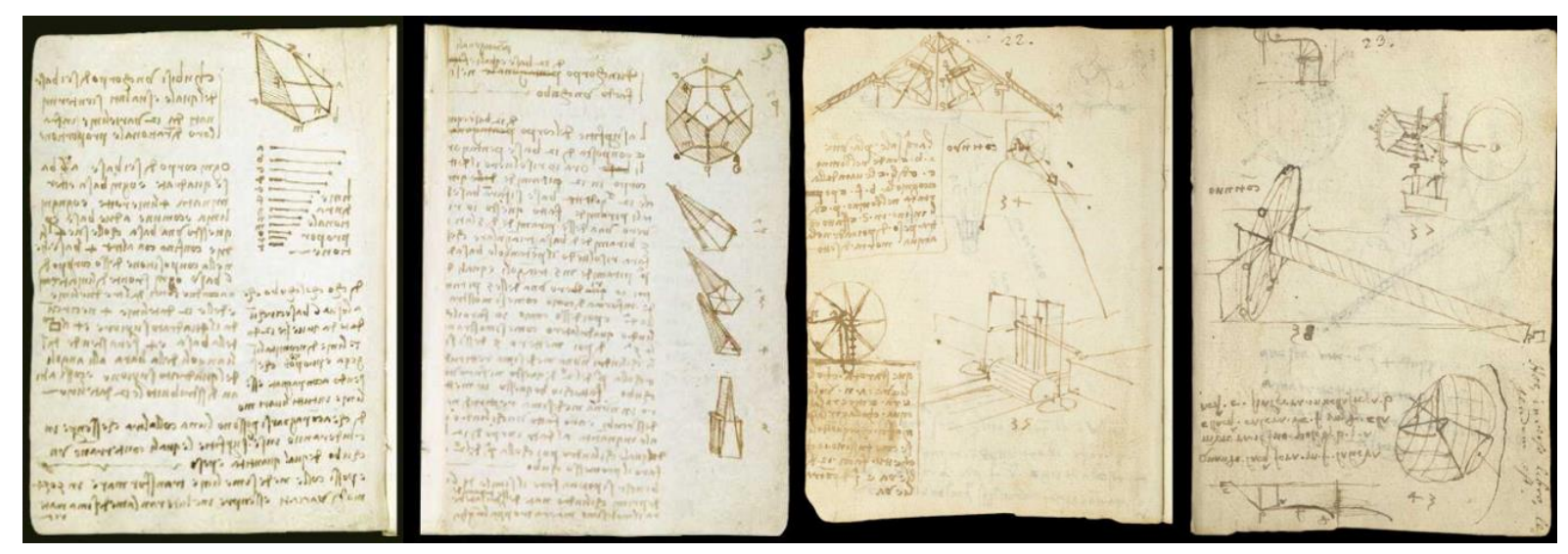

Fig. 1 Extracts from Leonardo de Vinci's notebook. (C) Victoria and Albert Museum, London

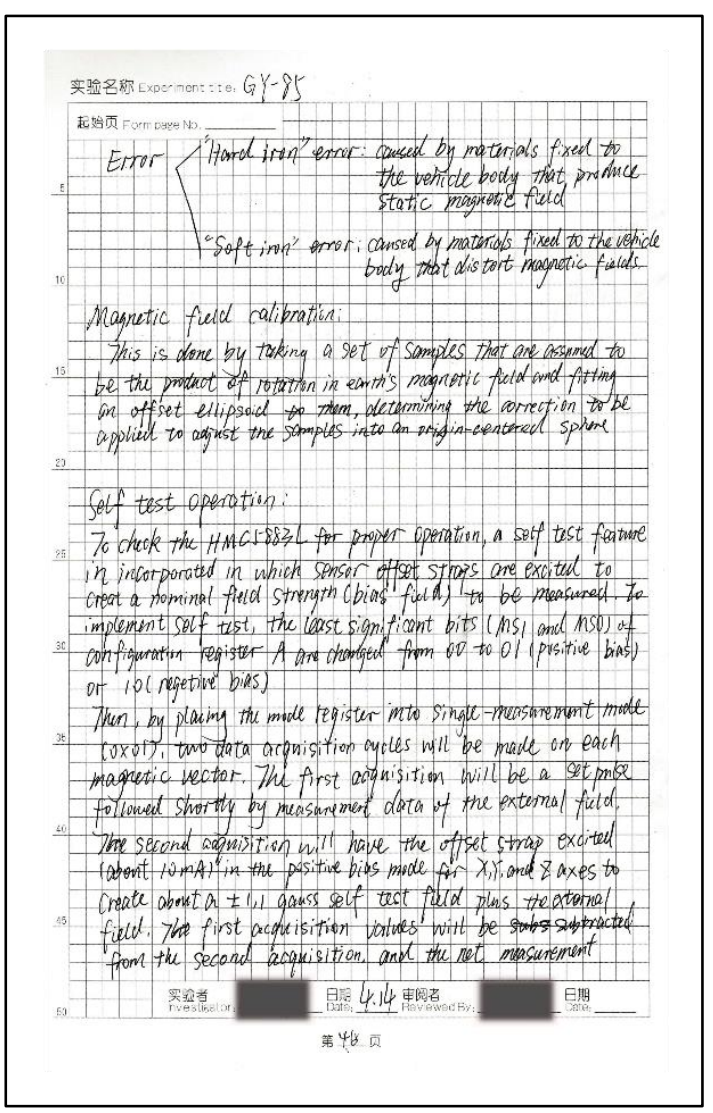

Fig. 2 Lab work ought to be recorded in a well maintained notebook. (a) An extract from a student's paper notebook.

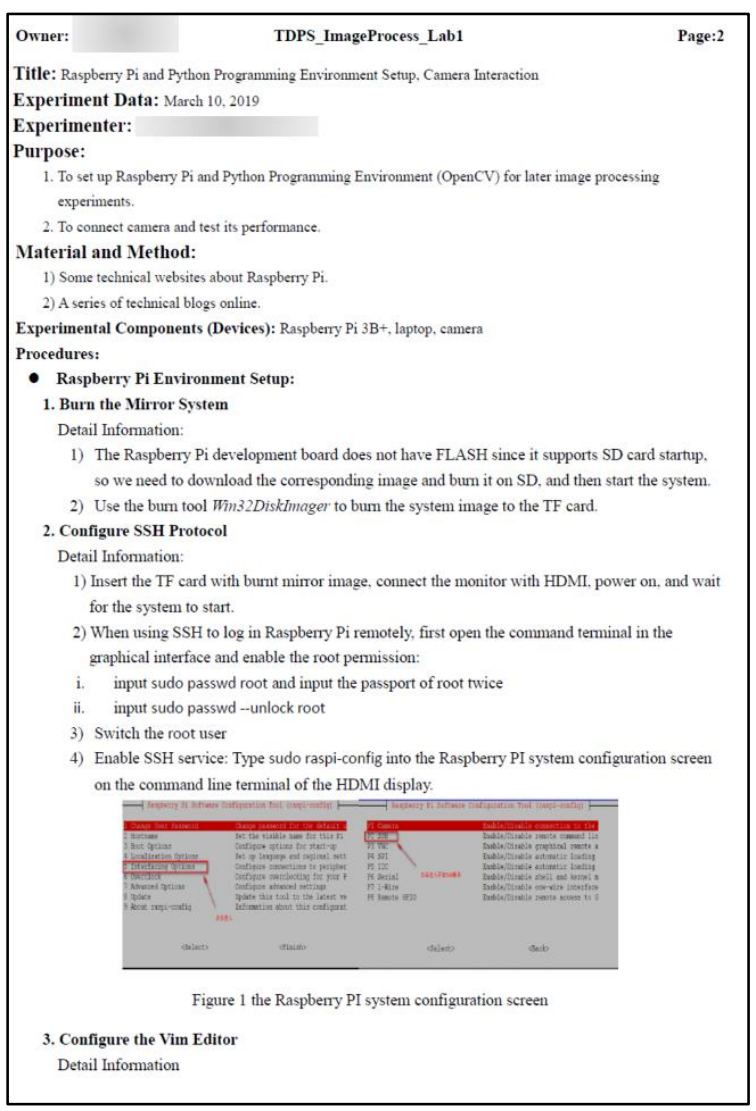

Fig. 3 An extract from a student lab notebook, which was developed using a dedicated ELN software product. 


\section{References}

Sawyer, R. K. 2005. The Cambridge handbook of the learning sciences, Cambridge University Press.

H. M. Kanare, Writing the laboratory notebook. ERIC, 1985.

Victoria and Albert Museum. "Explore Leonardo da Vinci's notebooks." https://www.vam.ac.uk/articles/leonardo-da-vincis-notebooks (accessed 18th October, 2019).

Harvard Medical School. "Harvard Biomedical Data Management: Electronic Lab Notebooks." https://datamanagement.hms.harvard.edu/electronic-lab-notebooks (accessed 7th November, 2019).

E. Walsh and I. Cho, "Using Evernote as an Electronic Lab Notebook in a Translational Science Laboratory," Journal of Laboratory Automation, vol. 18, no. 3, pp. 229-234, 2013, doi: 10.1177/2211068212471834.

C. Tachibana, "The paperless lab," Science, vol. 345, no. 6195, pp. 468-470, 2014.

J. D. Weibel, "Working toward a paperless undergraduate physical chemistry teaching laboratory," ed: ACS Publications, 2016.

\section{Biography}

Rami Ghannam is a lecturer (Assistant Professor) in Electronic and Nanoscale Engineering at the University of Glasgow. He obtained his PhD from the University of Cambridge, his MSc from Imperial College London and his Bachelor's degree from King's College. His research interests are in Photovoltaics and Engineering Education. 